\title{
DA RELAÇÃO ENTRE TRABALHO E SAÚDE À RELAÇÃO ENTRE TRABALHO E SAÚDE MENTAL
}

\author{
Izabel Cristina Ferreira Borsoi \\ Universidade Federal do Ceará, Fortaleza, Brasil
}

RESUMO: Diante das atuais transformações no mundo do trabalho, tornou-se essencial aprofundar o debate sobre a relação entre trabalho e saúde/saúde mental, bem como sobre o reconhecimento dessa relação, de modo a garantir amparo legal ao trabalhador e, principalmente, trazer subsídios para a busca de mudanças nas situações de trabalho. Este artigo se propõe: discutir este tema, pontuando as dificuldades para se estabelecerem relações entre determinados aspectos do trabalho e o adoecimento; apontar alguns limites e expectativas, bem como a necessidade de diálogos que permitam avançar tanto do ponto de vista teórico como também em relação à aplicação prática dos conhecimentos produzidos. Pretende, enfim, chamar a atenção para o trabalho como categoria fundamental à compreensão da subjetividade e do processo saúde/doença mental.

PALAVRAS-CHAVE: trabalho; saúde; saúde mental; sofrimento psíquico.

\section{FROM THE RELATIONSHIP BETWEEN WORK AND HEALTH TO THE RELATIONSHIP BETWEEN WORK AND MENTAL HEALTH}

ABSTRACT: Considering the changes that are taking place nowadays in the world of work, it became essential to deepen the debate on the existing relationship between labor and health/mental health, and also on its recognition, in order to guarantee legal support for workers, and mainly to bring contributions in search of transformations in labor situations. The purposes of this paper are: to argue that topic, pointing out the difficulties of determining connections between certain aspects of work and falling ill; to indicate some limits and expectations, as well as the necessity of interlocutions that enable advances both in theoretical terms and on what concerns to practical application of the knowledge generated. So, this paper intends to put in relief that work is fundamental to understand subjectivity and the mental health/ disease process.

KEYWORDS: work, health, mental health, psychological suffering.

Durante muito tempo, o trabalho humano não foi pensado como parte do conjunto de aspectos significativos da vida das pessoas, de modo a ser considerado também um fator importante na constituição de sofrimento psíquico. A herança genética, os aspectos orgânicos e/ou a história familiar e afetiva dos indivíduos geralmente foram vistos como as principais referências explicativas para problemas nesse campo.

Ironicamente, ainda hoje, mesmo grande parte dos médicos não costuma se preocupar em saber como seus pacientes trabalham para viver. Muitas vezes, sequer os estudiosos e/ou profissionais do campo da saúde mental se lembram de que os indivíduos têm uma vida "diurna", que pode compreender um longo período dedicado a uma faina obrigatória e necessária para garantir a própria sobrevivência e/ou a de suas famílias. Entretanto, se tomarmos a clínica psicológica, veremos que grande parte da clientela é formada por indivíduos para quem o trabalho é de algum modo organizador da vida (Vasques-Menezes, 2004). Mesmo assim, é comum manter-se um suposto distanciamento entre trabalho e saúde mental, como se o primeiro não pudesse dizer nada sobre o segundo, como se determinados aspectos objetivos e subjetivos do trabalho não pudessem atuar provocando adoecimento.
Diante desta constatação, e também diante do fato de que o mundo do trabalho tem passado por profundas mudanças, algumas questões se impõem: (a) O que dizer sobre o trabalho na atualidade, sobre a relação trabalho-saúde/ doença e, mais precisamente, sobre a relação trabalhosaúde/doença mental?; (b) Como demonstrar essa relação, de modo a se obter o reconhecimento dos transtornos relacionados ao trabalho e, assim, garantir tratamento adequado e amparo legal ao trabalhador?

Este artigo se propõe discutir a relação entre saúde/ saúde mental e trabalho, pontuando algumas dificuldades no reconhecimento dos determinantes dos processos de sofrimento e adoecimento; apontar limites e expectativas na área, chamando a atenção para a necessidade de diálogos que permitam avanços tanto no âmbito teórico quanto com referência à aplicação prática dos conhecimentos produzidos; e discutir a importância de se considerar a categoria trabalho como fundamental para a compreensão da subjetividade e do processo saúde/doença mental.

Antes, entretanto, é preciso um rápido mergulho naquilo que tem sido o trabalho na contemporaneidade $\mathrm{e}$ nas razões pelas quais é mais comum associarmos trabalho a dissabor, desprazer e sofrimento, e menos a realização e prazer. 


\section{$O$ que tem sido o mundo do trabalho}

Em 1844, ao discutir a alienação do trabalho, Marx (1993) dizia que o trabalhador foge do trabalho como foge da peste. Isso porque o trabalho, como meio de satisfação de necessidades humanas, surgia, antes de tudo, como fonte de infelicidade, de esgotamento, de mortificação e de negação da condição de humanidade do próprio trabalhador.

O capitalismo que Marx vivenciou está bastante distante daquele que experimentamos hoje. Naquele momento, diante da tecnologia disponível, era em jornadas extensas e em condições de trabalho extremamente duras que os trabalhadores conseguiam a produção necessária para atender às expectativas e desejos de lucros dos donos das fábricas. Salários rebaixados e irregulares, exploração desmedida do trabalho de homens, mulheres e crianças e condições de vida aviltantes completavam a cena. Diante de tal situação, a preocupação dos trabalhadores centravase em sua própria sobrevivência, independentemente de sua condição de saúde. O lema da época era: "viver, para o operário, é não morrer". ${ }^{2}$

Frente ao quadro existente naquele momento, e como resultado de pressões dos próprios trabalhadores, as primeiras intervenções do Estado sobre a situação de trabalho nas fábricas regulavam, principalmente, a extensão das jornadas (Marx, 1983), o trabalho infanto-juvenil e as condições sanitárias. Com isso, preservava-se minimamente a integridade física dos trabalhadores.

Se o século XIX foi marcado por jornadas extensas, condições laborais aviltantes, pouca regulamentação das relações de trabalho etc., o século XX teve como marca principal um intenso processo de industrialização e, com ele, um acelerado avanço tecnológico, associado à adoção de modelos de gestão dos processos produtivos cada vez mais exigentes em termos da capacidade física e psíquica dos indivíduos.

Os resultados disso se fizeram sentir, em primeiro lugar, ainda no corpo do próprio trabalhador, em razão da lógica taylorista-fordista de organização do trabalho (Dejours, 1992), o que justificou, principalmente, as lutas pela manutenção da saúde física nas situações de trabalho e a exigência de maior regulamentação das condições laborais por parte do Estado.

No caso brasileiro, essa regulamentação se deu de forma lenta e gradativa, respeitando certo caráter de maior ou menor visibilidade dos agravos sofridos pelos trabalhadores. A título de exemplos: a primeira lei que regulava a indenização por acidente de trabalho foi aprovada somente em 1919 (Rocha \& Nunes, 1994), enquanto que as Inspetorias Regionais do Ministério do Trabalho surgiram em 1932 e, mais tarde - 1957 -, foram transformadas em Delegacias Regionais do Trabalho (Scopinho, 2003).
A partir do final da década de 1960 e início dos anos 1970, o processo crescente de automação do trabalho, aliado aos novos modelos de gerenciamento (como é o caso do toyotismo), deslocou, em parte, o eixo de exigências postas para os trabalhadores. Não houve a eliminação da demanda pela capacidade física do trabalhador, mas, por certo, houve um aumento significativo das exigências da sua capacidade psíquica, razão pela qual se pode afirmar que é principalmente sobre esta dimensão do trabalhador que passa a se dar o impacto do trabalho.

Em se tratando dos modelos de gestão, não é possível afirmar que houve a superação ou a substituição efetiva de um pelo outro. O que se nota é que, de um lado, os trabalhadores continuam enfrentando a cisão entre planejamento e execução, bem como o rompimento entre o saber e o fazer, típicos do modelo taylorista-fordista de produção, enquanto que, de outro, são submetidos a um processo no qual, supostamente, lidam com a recomposição das tarefas e têm o controle da produção em suas mãos, a exemplo do toyotismo, como mostra Antunes (1995).

Nesse contexto, o que tem imperado em todos os setores de produção, seja de bens ou de serviços, é a busca de uma produtividade cada vez maior, sendo hegemônico o discurso da qualidade do produto-mercadoria, com vistas à satisfação de um quase onipresente cliente-consumidor. Guardando as devidas diferenças, isso vale tanto para um trabalhador da indústria de calçados ou da indústria química quanto para um atendente de call center ou um professor do ensino superior.

O que, afinal, podemos notar é que a atividade humana chamada trabalho praticamente tem se restringido àquilo que Hanna Arendt (2001) denomina labor, ou seja, uma atividade vinculada à sobrevivência imediata e que se perpetua na repetição dos gestos e do que ela produz; uma atividade na qual o trabalhador não domina o processo e não detém o produto, sendo servo e não senhor da matéria que trabalha. ${ }^{3}$ Para Arendt, seria ocioso até mesmo perguntar "se os homens vivem e consomem para ter forças para trabalhar ou se trabalham para ter os meios de consumo" (p. 159).

Essa laborização parece tornar-se cada vez mais marcante no mundo do trabalho, na contemporaneidade, intensificando os prejuízos à integridade física e psíquica dos trabalhadores, em que pese a existência de condições tecnológicas que bem poderiam levar ao contrário.

\section{A relação entre trabalho e saúde/saúde mental: problemas e limites}

Diante do que foi exposto até aqui, cabe perguntar: o que ocorre à saúde dos trabalhadores e, mais especificamente, à sua saúde mental? Que o trabalho, nas condições e na forma como vem sendo realizado, em grande parte das vezes tem sido danoso à saúde dos trabalhadores é 
fato notório. O problema é como demonstrar essa relação de maneira que ela ganhe estatuto legal, visando a proteger o trabalhador. Cabe lembrar que, para o trabalhador ter acesso aos benefícios do seguro do Instituto Nacional de Seguridade Social (INSS), em caso de acidente de trabalho, é preciso que haja o estabelecimento do que se conhece como nexo causal (Rigotto \& Rocha, 1993). Essa determinação está relacionada a uma visão de saúde no trabalho centrada na interpretação uni ou multicausal dos fenômenos relacionados à saúde/doença. Nesse caso, o que se leva em conta é o fato de que "elementos ou fatores de risco específicos, quando atuam no organismo, causam enfermidades também específicas, legalmente reconhecidas como doenças profissionais ou relacionadas ao trabalho" (Scopinho, 2003, p. 97).

Em se tratando de acidente de trabalho típico, é fácil reconhecer o agente causador do dano e o próprio dano. Em se tratando de doenças ocupacionais, entretanto, essa relação nem sempre é diretamente palpável ou visível, ou seja, nem sempre é possível identificar, de forma objetiva, os determinantes da doença, para que esta seja reconhecida como profissional ou relacionada ao trabalho. Exemplos disso são os casos de perda auditiva provocada por trabalhos realizados em condições de excessivo ruído. $\mathrm{O}$ fato de o trabalhador nem sempre apresentar déficit auditivo bilateral, embora ambos os ouvidos tenham estado igualmente expostos ao ruído, é razão suficiente para que o problema não seja reconhecido como acidente de trabalho. E, não havendo o devido reconhecimento, o trabalhador permanece sem amparo legal e, portanto, sem acesso aos direitos que teria como acidentado, conforme mostra Borsoi (2005). ${ }^{4}$

$\mathrm{Se}$, muitas vezes, não se encontra respaldo suficiente para que determinados processos de adoecimento entre trabalhadores sejam qualificados como relacionados ao trabalho, no campo da saúde/doença mental a dificuldade se torna ainda maior, na medida em que não está dado esse caráter palpável, ou relativamente palpável, encontrado nos problemas que atingem diretamente o corpo. Aqui, navegamos em mar revolto - quando não pisamos em areia movediça. Isso porque, entre outras coisas, "não é possível quantificar a vivência, que é em primeiro lugar qualitativa" (Dejours, 1994, p. 22).

A dificuldade começa quando se tenta encontrar consensos sobre o que entender por saúde mental/doença mental e, em decorrência, por sofrimento psíquico. Borges e Argolo (2002, p. 272) afirmam que "saúde e doença mentais não são situações que permitam definir uma como ausência da outra." Mas, em geral, a clínica e a epidemiologia consideram critérios básicos para a classificação das doenças mentais "a presença de alterações, desintegração no funcionamento psíquico e a duração dessas alterações." No entanto, esse modelo de compreensão exclui situações em que há sofrimento psicológico sem que este possa ser definido como uma doença ou transtorno mental no sentido clássico.

Nesse contexto, é preciso destacar até mesmo o fato de que nem sempre o indivíduo identifica seu sofrimento como sendo de ordem psíquica. E mesmo que o perceba assim, muitas vezes não lhe confere a dimensão necessária para buscar ajuda. Por fim, quando o faz, raramente associa seu sofrimento a situações de trabalho, mesmo porque, geralmente, os problemas ditos pessoais ganham o direito de se expressar somente depois da jornada de trabalho.

Há um segundo aspecto importante que dificulta encontrarmos elementos que sirvam de base para estabelecer a relação entre trabalho e sofrimento psíquico: nas organizações, não é muito comum o diagnóstico de casos graves ou claramente delineados como doença mental ou transtorno mental. Isto porque, se o sofrimento ocorre, antes de ele tornar-se um problema para a organização, o trabalhador tende, de algum modo, a se afastar de sua atividade, ou dela é afastado, com diagnósticos que geralmente não refletem o que de fato sofre. Um exemplo disso são os chamados "desembarques brancos" realizados por petroleiros que trabalham em plataformas marítimas. Quando não suportam mais o trabalho confinado, e antes que percam o equilíbrio necessário para se manter embarcados, buscam justificativas para desembarcar, continuando a trabalhar como petroleiros em terra (Sampaio, Borsoi \& Ruiz, 1998).

Um terceiro aspecto diz respeito à consideração, que muitas vezes se tem, de que os indivíduos entram no mundo do trabalho pelo menos ao final da adolescência e já portando uma bagagem mínima de escolaridade e qualificação. Essa consideração, longe de ser verdadeira na grande maioria dos casos, dificulta que se compreenda o grau em que a subjetividade é constituída pelo trabalho e em que medida este pode ser causador de transtornos psíquicos.

Diante disso, quando se trata de compreender a relação entre saúde mental e trabalho, é preciso, a meu ver, considerar alguns aspectos:

1. Os indivíduos nascem num contexto no qual o trabalho é a base da sobrevivência do próprio grupo ao qual pertence.

2. Diferentemente da situação que muitas vezes se toma como referência, grande parte dos indivíduos entra no mercado de trabalho sem sequer ter vivido as transformações do corpo próprias da adolescência, a definição da identidade sexual, as primeiras experiências amorosas etc.

3. Quando um indivíduo ingressa no mundo do trabalho, começa a organizar sua vida em função das exigências desse novo lugar, e é lá que deixa a maior parte de suas melhores horas do dia-durante a maior parte de sua vida, daí em diante. 
Em síntese, quando o trabalho começa a fazer parte efetiva da vida das pessoas, ele se torna tão significativo (ou quase) quanto as relações amorosas que elas constroem e - a meu ver, não seria exagero dizer - tão necessário quanto o sono. Sem trabalho, não teremos como satisfazer necessidades básicas do nosso corpo e da nossa fantasia. Apesar disso, o trabalho só bem tardiamente passou a integrar, de modo efetivo e sistemático, o campo das preocupações presentes nos estudos sobre saúde mental.

No que diz respeito à saúde/doença mental, mais especificamente, é preciso considerar ainda que se trata de um processo que expressa determinadas condições da vida humana e também determinada capacidade dos indivíduos para o enfrentamento dos desafios, conflitos e agressões apresentados pela realidade na qual vivem. Com base nessa compreensão, sofrimento psíquico e doença mental podem ser tomados como processos qualitativamente distintos. No primeiro caso, diz respeito a um conjunto de mal-estares que se caracteriza pela "dificuldade do sujeito em operar planos e definir sentidos para a vida, aliada a sentimento de impotência e vazio, o eu sendo experimentado como coisa alheia" (Sampaio \& Messias, 2002, p. 151). No segundo, trata-se de um:

modo de reapropriação individual, que revela o fracasso das tentativas de entender, superar, evitar ou tornar suportável os sofrimentos psíquicos, radicalizando o processo de alienação e fazendo o sujeito viver tensões sem expectativa de solução ou abolir aparencialmente os pólos de tensão entre parteltodo, essêncialaparência, indivíduo/sociedade, consciêncialobjetividade (Sampaio \& Messias, 2002, p. 151).

As dificuldades em estabelecer a relação entre determinadas formas de trabalho e sofrimento psíquico levaram, na curta história dessa área de estudos, ao surgimento de diferentes modos de investigar e compreender o problema. De acordo com Jacques (2003), podemos identificar claramente, a esse respeito, quatro amplas abordagens: as teorias sobre estresse; a psicodinâmica do trabalho, de base psicanalítica; a abordagem epidemiológica e/ou diagnóstica; e os estudos sobre subjetividade e trabalho que se realizam numa perspectiva sócio-histórica. Tendo em vista a existência de trabalhos mais específicos sobre essa temática (Codo, Soratto \& Vasques-Menezes, 2004; Jacques, 2003), restrinjo-me a oferecer apenas uma síntese dessa discussão, de modo a permitir avançar o debate proposto neste artigo.

O conceito de estresse, além de ser muito utilizado entre pesquisadores da área da saúde, é também amplamente disseminado nos meios de comunicação, integrando nossa linguagem cotidiana. Originalmente empregado na física para definir o desgaste de materiais sob efeitos de peso, calor ou radiação, o termo "estresse" foi, posteriormente, adotado pelo médico Hans Selye para denominar a "síndrome geral de adaptação", um processo de dimensão biológica que caracteriza a resposta de um organismo a situações de ameaça no ambiente, sendo, portanto, em última instância, uma reação natural de defesa (Codo, Soratto \& Vasques-Menezes, 2004; Filgueiras \& Hilppert, 2002; Jacques, 2003).

Mais tarde, o conceito de estresse passou a ser utilizado para definir a relação entre uma pessoa e o ambiente percebido como prejudicial ao seu bem-estar (Lazarus \& Folkman, 1984, citado por Jacques, 2003). Surge, então, o que conhecemos como estresse psicológico, que ressalta tanto a importância da avaliação cognitiva que o indivíduo faz da situação de ameaça como, também, suas formas de enfrentamento dessa mesma situação. ${ }^{5}$

Como a noção de estresse psicológico designa quaisquer situações de adaptação do indivíduo, independentemente de estas serem (ou não) relacionadas ao trabalho, foi necessário delimitar o campo de compreensão do problema. É daí que surgem conceitos como estresse profissional e burnout. Este último designa uma síndrome de esgotamento profissional e se caracteriza por "uma reação à tensão emocional crônica gerada a partir do contato direto e excessivo com outros seres humanos, particularmente quando estes estão preocupados ou com problemas" (Codo \& Vasques-Menezes, 1999, p. 238).

A segunda abordagem - por sinal, uma das que mais influenciaram pesquisadores brasileiros - é a psicodinâmica do trabalho, proposta por Dejours. Seu livro A loucura do trabalho, publicado pela primeira vez no Brasil em 1987, abriu uma perspectiva bem distante da abordagem fisiológica característica dos estudos sobre estresse.

Pagando tributo à visão psicanalítica dos processos psíquicos, Dejours (1992) propõe uma compreensão da relação entre trabalho e saúde mental, pondo fundamentalmente na história primária dos indivíduos a principal razão do modo de expressão do sofrimento psíquico. $\mathrm{O}$ trabalho, nesse caso, define o momento da expressão do sofrimento, mas não sua forma, que, por sua vez, resulta da estrutura psíquica característica do indivíduo.

Para esse pesquisador, o trabalho pode ser considerado pelo indivíduo como equilibrante ou fatigante. Será equilibrante se permitir a expressão do desejo do indivíduo e se, de fato, configurar-se como lugar de sublimação. Será fonte de sofrimento psíquico se o desejo precisar ser reprimido, por não encontrar ressonância naquilo que $o$ indivíduo faz.

A proposta de Dejours tem recebido grande aceitação entre estudiosos do campo da saúde do trabalhador, mas também tem sido alvo de fortes críticas, principalmente em relação a seu modelo metodológico e ao lugar reservado ao trabalho em sua teoria. O método que propõe é fundamentado no modelo clínico, especialmente de base psicanalítica, e põe sua ênfase no discurso do trabalhador, 
em detrimento da objetividade dos fatos por ele vividos. Por decorrência, o trabalho é tratado como uma categoria marginal e só é abordado por meio da fala, ou seja, através da visão subjetiva que o trabalhador tem sobre ele (Lima, 2002).

Uma terceira abordagem teórico-metodológica, qualificada como epidemiológica e/ou diagnóstica, surge no Brasil no final da década de 1980, a partir da proposta desenvolvida por Codo e colaboradores (Codo, Sampaio \& Hitomi, 1992; Codo, Soratto \& Vasques-Menezes, 2004; Jacques, 2003; Sampaio \& Messias, 2002). Neste caso, a compreensão da relação entre trabalho e saúde mental parte das concepções de homem e de trabalho formuladas pelas teorias marxistas, bem como da consideração da epidemiologia enquanto

ciência social, prática, aplicada, que estuda distribuição, determinação e modos de expressão, para fins de planejamento, prevenção e produção do conhecimento, de qualquer elemento do processo saúdel doença, em relação a população qualificada nos elementos socioeconômico-culturais que a possam tornar estruturalmente heterogênea (Sampaio \& Messias, 2002, p. 146-147).

O que essa abordagem busca mostrar é que o trabalho, dependendo das condições e da maneira como é realizado, determina modos específicos de sofrimento psíquico. $\mathrm{Ou}$ seja, mais que definir o momento da emergência desse sofrimento, como defende Dejours, o trabalho definiria seu conteúdo e sua forma. Assim, parte-se do estudo de categorias profissionais, buscando realizar o diagnóstico tanto da organização na qual os trabalhadores estão inseridos quanto da saúde mental da categoria em questão. Feito isso, o passo seguinte será identificar aspectos do trabalho que possam estar relacionados ao perfil de sofrimento apresentado por essa categoria de trabalhadores.

Uma quarta abordagem articula subjetividade e trabalho, procurando "analisar o sujeito trabalhador a partir de suas experiências e vivências adquiridas no mundo do trabalho" (Jacques, 2003, p. 10). Tal como Dejours, considera fundamental a vivência do trabalhador e não se restringe aos aspectos psicopatológicos do trabalho. Entretanto, marca determinada distância em relação à proposta dejouriana ao fundamentar-se em princípios marxistas para a compreensão da relação entre a situação de vida e de trabalho e o processo saúde-doença, considerando o trabalho como eixo central para a compreensão da subjetividade humana.

Por incorporar a noção de experiência, da forma como foi proposta por Thompson (1981), essa abordagem leva em conta o fato de que os indivíduos são construtores de seu processo de vida, são concretos e contextualizados histórica e culturalmente. Sendo assim, toda a história do trabalhador deve ser considerada relevante para a com- preensão do sofrimento que ele possa apresentar. O que se argumenta é que o trabalho pode construir modos de sofrimento, na medida em que ele é também constituinte fundamental da subjetividade dos indivíduos, é parte de suas experiências.

Enfim, cada uma das abordagens apresentadas busca, a seu modo, encontrar a relação entre trabalho e saúde mental, tentando apontar os nexos entre aspectos do trabalho e sofrimento psíquico. Pode-se notar que, apesar das distâncias teórico-metodológicas existentes entre elas, há, pelo menos, um consenso: desencadeador, determinante ou constituinte, o trabalho pode ser considerado, de alguma maneira, motivo de sofrimento que muitas vezes limita o trabalhador, quando não o impede efetivamente de trabalhar.

Trabalho, saúde/sofrimento psíquico:
campo de possibilidades e expectativas

Não é tarefa fácil - muitas vezes, sequer é possível encontrar modos relativamente definidos de sofrimento, a exemplo da conhecida "neurose das telefonistas", descrita em 1956 por Le Guillant et al. (1984), ou da síndrome de burnout. Se o trabalho é, como afirma Dejours (2005, p. 141), "uma fonte inesgotável de paradoxos", então, nem sempre um conjunto de mal-estares terá características claras que lhe permitam ser associado ao trabalho; nem sempre o sofrimento do trabalhador se expressará conforme o conteúdo e a forma do trabalho realizado; nem sempre o trabalho será o principal fator determinante, podendo ser, quando muito, um importante fator deflagrador de sofrimento.

Entretanto, as considerações acima não deveriam consistir um entrave para o debate e para as definições práticas que o problema exige. O fundamental, a meu ver, é a compreensão de que o trabalho é um momento significativo entre outros momentos significativos na vida dos indivíduos, independentemente do caminho teórico que possamos adotar. Se nossa humanidade só é possível a partir da singularidade do mundo dos afetos e do mundo do trabalho, então é necessário o reconhecimento prático do trabalho como dotado também de significado especial na vida das pessoas que dele vivem.

Partindo da definição de Freud de que saúde mental é a "capacidade de amar e de trabalhar", Codo, Soratto e Vasques-Menezes (2004, p. 279) reivindicam para o trabalho lugar similar ao que a psicanálise reservou à sexualidade na compreensão dos seres humanos. Para esses autores, "saúde mental é a capacidade de construir a si próprio e à espécie, produzindo e reproduzindo a si próprio e à espécie". Portanto, "distúrbio psicológico, sofrimento psicológico ou doença mental são o rompimento dessa capacidade".

Apesar de haver o reconhecimento de que a saúde mental está relacionada a aspectos da vida situados fora e 
dentro do trabalho, o dilema se mantém e a dicotomia se faz presente, quando se trata de discutir o sofrimento ou a doença mental. Por um lado, tenta-se pôr entre parênteses a história de vida que os indivíduos constroem antes (ou fora) do trabalho, na tentativa de encontrar o exato lugar do trabalho na constituição de seu sofrimento. Por outro lado - o que é mais freqüente -, busca-se exorcizar, ou, no mínimo, desconsiderar o trabalho na história de sofrimento dos mesmos indivíduos. Por fim, conforme apontam, criticamente, Sato e Bernardo (2005), pode-se também tomar o trabalho, suas condições e sua organização como mero pano de fundo.

É preciso considerar que, mesmo em casos de doenças com manifestação basicamente orgânica, deve-se considerar, além dos aspectos relacionados ao trabalho, também a história do trabalhador no que toca às suas condições de vida, à sua própria saúde e à de sua família etc. Essas informações são fundamentais para se compreender por que, numa determinada condição laboral, na qual estão presentes determinados agentes agressivos, nem todos os trabalhadores adoecem do mesmo modo, como ocorre, por exemplo, com a LER. ${ }^{6}$ Neste caso, embora se trate de uma patologia que atinge partes específicas do corpo, ela se manifesta por sintomas difíceis de serem detectados através dos sentidos tátil ou visual, ou, ainda, por meio de exames complementares. Seu diagnóstico é, fundamentalmente, baseado no relato do paciente que sente a dor, esta entendida como "de ordem subjetiva, uma experiência absolutamente individual, imensurável, intocável e invisível" (Barros \& Guimarães, 1999, p. 84). Entretanto, o caráter, de certo modo, enigmático que caracteriza essa síndrome não autoriza a reduzi-la a uma forma de manifestação da estrutura neurótica do trabalhador, como chegou a defender Almeida (1995) ao associá-la a sintomas histéricos. Para Lima (1997), a compreensão da LER exige que se busque a interação dos aspectos psicológicos com os fatos da realidade vivida pelo trabalhador, a qual, nesse caso, é uma realidade de trabalho caracterizada pela repetição das tarefas, por problemas ergonômicos, por exigência de produtividade etc.

Se a singularidade dos indivíduos, suas histórias de vida, sua suscetibilidade ou predisposição devem ser consideradas na compreensão de processos de adoecimento de base e expressão orgânicas, a preocupação deveria ser semelhante no campo da saúde mental. Basaglia (1980, p. 79) afirmava que a doença mental, como todas as doenças, expressa as

... contradições do nosso corpo, e dizendo corpo, digo corpo orgânico e social. É nesse sentido que direi que a doença, sendo uma contradição que se verifica no ambiente social, não é um produto apenas da sociedade, mas uma interação dos níveis nos quais nos compomos: biológico, sociológico, psicológico.
Se os modos humanos de viver incluem o lugar do trabalho, da sexualidade e da família; se a história de vida das pessoas é também a sua história biológica e a história dos momentos percebidos por elas como significativos - se é assim, para qualificar e compreender os modos de sofrimento psíquico relacionados ao trabalho (sejam eles configurados ou não como transtorno ou doença mental), é necessário, além de considerar a concretude da situação de trabalho, levar em conta os vários aspectos da história do trabalhador, bem como seu modo de significar os eventos marcantes da sua vida.

Neste sentido, Tavares (2004, p. 55), a partir de sua experiência clínica, reconhece que determinados aspectos reais da situação de trabalho podem produzir sofrimento psíquico em muitas pessoas, devendo ele ser tratado, prioritariamente, como um problema relacionado ao trabalho. Por outro lado, afirma que há situações de sofrimento que são resultado da experiência de vida dos indivíduos localizada fora do seu contexto de trabalho. Entretanto, considera que o sofrimento é resultado da interação dos aspectos do trabalho e da história das pessoas. "A ressonância entre questões do trabalho e aspectos da experiência e da história do sujeito, portanto, a ressonância de fatores objetivos e subjetivos, é responsável pela maior parte do sofrimento na situação de trabalho."

Lima (2002), por sua vez, afirma ser preciso levar em conta tanto o discurso do trabalhador quanto os aspectos objetivos de seu trabalho. Assim, para articular objetividade e subjetividade, de modo a compreender efetivamente o comportamento humano no trabalho, é necessária "a compreensão da subjetividade concreta", no verdadeiro sentido politzeriano (Lima, 2002, p. 80). A autora defende que é preciso evitar cair tanto no subjetivismo, que se restringe à pura interioridade dos indivíduos, quanto no objetivismo, que toma a realidade como pura exterioridade contraposta aos sujeitos. ${ }^{7}$

Considerando o que foi exposto até aqui, a meu ver, deveria valer também para a compreensão e o reconhecimento dos casos de saúde mental a recomendação que Barros e Guimarães (1999, p. 83) fazem para se reconhecer uma queixa de LER: é necessária "ao profissional de saúde uma escuta sem preconceitos dos sofrimentos que lhe são relatados, de maneira que possa estar sensível para ouvir mais do que ver, e entender mais do que medir."

É importante considerar que as pessoas vivem nas intersecções das várias esferas da vida e da variedade de significados e sentidos que constroem tanto individual como coletivamente. Portanto, a subjetividade é também construída na história dessas intersecções e, como afirma Sato (2002, p. 43),

... se expressa de diversas formas - instituições criadas (formas de relação, códigos, ritos, regras, valores, etc.) e as práticas - sendo a verbalização apenas 
um dos canais de sua expressão. Isto significa que o estudo da subjetividade não se restringe ao que as pessoas 'pensam ou conhecem', mas ao que 'faz sentido' para elas, porque pode estar no âmbito dos costumes, uma espécie de segunda natureza, incorporada em hábitos, 'um comportamento inercial, induzido e habitual.' (apud Thompson, 1993, p. 2). ${ }^{8}$

Se é assim, a saúde e o sofrimento ou transtorno psíquico devem ser pensados também como resultados da história dessas intersecções. Portanto, resgatar aspectos do trabalho para a compreensão dos processos subjetivos e dos processos de adoecimento psíquico do trabalhador não significa isolar, dos demais aspectos de sua história de vida, seu percurso profissional anterior e sua situação imediata de trabalho.

Ao contrário, o que se busca é a articulação das várias histórias que o trabalhador apresenta para dizer da dimensão do seu sofrimento - tanto aquelas qualificadas como objetivas, que podem ser submetidas ao crivo da observação ou verificação, como também as que entendemos como subjetivas, e que são de difícil apreensão, não se oferecendo facilmente à nossa compreensão, por estarem relacionadas às representações e aos sentidos que o trabalhador lhes empresta.

O que está em questão é, ao fim, a concretude da realidade e do sofrimento experimentados pelos trabalhadores, mesmo porque a diversidade das situações vividas cotidianamente por eles "não respeita as fronteiras teóricometodológicas" (Sato \& Bernardo, 2005, p. 3), exigindo, portanto, diálogo crítico e constante entre as várias disciplinas que buscam compreender o problema. Para além destes aspectos, estão questões concretas e práticas que os atingem diretamente e que aguardam respostas também concretas e práticas da parte dos pesquisadores e profissionais de saúde.

Embora os avanços no campo de estudos sobre saúde mental e trabalho tenham sido significativos, é preciso admitir que isso ainda não garantiu aos trabalhadores o respaldo suficiente para que tenham direitos a benefícios em razão de adoecimento psíquico provocado em situação laboral. Aqueles avanços também não têm resultado ainda em mudanças efetivas, em maior escala, nas condições objetivas e na organização do trabalho.

Entretanto, é certo que esses estudos podem oferecer - e têm oferecido-elementos importantes para fundamentar reivindicações sindicais em torno da saúde mental dos trabalhadores. Têm criado, também, uma base importante de conhecimento para auxiliar os profissionais de saúde física e mental na identificação e no diagnóstico de sofrimento ou transtorno psíquico dos trabalhadores que os procuram. Isso, por sua vez, poderia, entre outras coisas, reverter o quadro de subnotificação de problemas de saúde mental relacionados ao trabalho, situação que ainda é co- mum no Brasil, a julgar pelo que mostram Sato e Bernardo (2005). As autoras, tomando por base o Centro de Referência de Saúde do Trabalhador (CRST) de Campinas, mostram que dificilmente são diagnosticados durante os atendimentos nesse serviço problemas como depressão não-orgânica, estresse e transtornos do sono relacionados ao trabalho. Considerando os diagnósticos principais fundamentados na Classificação Internacional de Doenças (CID 10), esses transtornos psíquicos representaram, naquele CRST, durante o ano de 2004, menos de 1\% dos 892 diagnósticos médicos atribuídos aos novos pacientes, enquanto que os casos de LER corresponderam a quase $70 \%$ do total.

Embora muitos dos aspectos discutidos aqui apontem mais reflexões e desafios do que soluções prontas, uma conclusão importante parece possível. A compreensão da relação entre saúde/doença mental e trabalho, a busca de respostas concretas para o adoecimento psíquico oriundo das situações de trabalho, o reconhecimento dos determinantes da doença ou do sofrimento psíquico, as efetivas mudanças que possam ser geradas pelos resultados encontrados neste campo - tudo isso será fruto do diálogo, do esforço e do trabalho de um conjunto de atores, dentre os quais estão os profissionais de saúde responsáveis pelo atendimento médico e psicológico, os estudiosos do tema, os sindicalistas e, sobretudo, os próprios trabalhadores, que ainda precisam tomar consciência de algo fundamental: o sofrimento ou o transtorno psíquico deve ser considerado como queixa legítima e, por esta razão, deve ter o mesmo estatuto de qualquer outra queixa de doença relacionada ao trabalho, independentemente do lugar onde ela for relatada, seja nas empresas, na perícia do INSS, nos CRST, nos consultórios de médicos ou de psicólogos.

\section{Notas}

Agradeço a Izildo Corrêa Leite a leitura atenta que resultou em contribuições importantes para a finalização deste artigo.

2 Afirmação de G. Guerin, citada por Bron. Histoire du mouvement ouvrier. Vol. 1, p. 45. (apud Dejours, 1992, p. 161).

3 Originalmente, "laborar significa ser escravizado pela necessidade, escravidão esta inerente às condições de vida humana" (Arendt, 2001, p. 94).

4 A autora aponta algumas das dificuldades encontradas por trabalhadores de fábricas, localizadas no interior do Ceará, para terem reconhecidos os danos auditivos causados pelo excessivo ruído produzido na linha de produção. Médicos dos postos de saúde que atendiam a esses trabalhadores afirmaram que era comum serem procurados por indivíduos que apresentavam algum nível de déficit auditivo após determinado período de trabalho. Nesses casos, a angústia do trabalhador se devia, muitas vezes, ao risco de ser descartado da produção fabril por causa do déficit, mesmo que este fosse relativamente pouco significativo. Também os sindicatos, freqüentemente, encontravam-se diante da tarefa de buscar respaldo para comprovar o dano sofrido pelos trabalhadores, de modo a justificar, assim, uma indenização ou algum benefício legal. 
5 O conjunto de estratégias utilizadas pelo indivíduo para enfrentar ou se adaptar à situação estressante foi denominado de coping, termo sem tradução para o português (Filgueira \& Hilppert, 2002; Jacques, 2003).

6 A sigla LER, Lesões por Esforços Repetitivos, vem do original "repetition strain injuries". Atualmente, tem-se adotado a expressão LER/DORT, na qual DORT refere-se a Distúrbios Osteomusculares Relacionados ao Trabalho e vem do original inglês "Work-related musculoskeletal disorders".

7 Um exemplo claro da riqueza da articulação entre a objetividade da situação de trabalho e a objetividade/subjetividade manifesta na história de vida e sofrimento do trabalhador é o caso analisado por Lima, Assunção e Francisco (2002). Trata-se de um transtorno psíquico grave sofrido por um porteiro de um condomínio de garagens que era obrigado a lidar com uma situação de trabalho cuja rotina e controle eram extremamente rígidos. O controle era realizado através de um relógio que deveria ser acionado em intervalos regulares de tempo, visando a controlar a permanência e a atenção dos trabalhadores em seus postos de trabalho. Os sintomas surgidos durante o período de trabalho permaneciam mesmo depois do afastamento de suas atividades e já em tratamento por algum tempo. Os autores destacam que, para compreender o adoecimento desse trabalhador, foi necessário resgatar sua trajetória de vida, considerando determinada rigidez da educação e dos valores familiares, aspectos de sua personalidade, seu histórico anterior de saúde, bem como seu percurso profissional desde suas primeiras experiências laborais. Enfatizam que aquele trabalho específico, com sua organização patogênica, fez eclodir o processo de adoecimento. Afirmam, por fim, que "o que devemos tentar compreender é o modo pelo qual se articulam as características pessoais e certas condições de vida e de trabalho, sem jamais desconsiderar a prioridade ontológica das últimas sobre as primeiras” (Lima, Assunção \& Francisco, 2002, p. 246).

8 Nessa passagem, a autora se refere à obra de E. P. Thompson intitulada Customs in common. Studies in tradicional popular culture. New Work: The New Press, 1993 - o que, por sua vez, explica o uso de parênteses para referir o autor na citação.

\section{Referências}

Almeida, M. C. C. G. (1995). Em busca de uma linguagem. In W. Codo \& M. C. C. G. Almeida, (Eds.), L.E.R. - Lesões por esforços repetitivos (pp. 110-135). Petrópolis, RJ: Vozes.

Antunes, R. (1995). Adeus ao trabalho? - Ensaio sobre as metamorfoses e a centralidade do mundo do trabalho. São Paulo, SP: Cortez.

Arendt, H. (2001). A condição humana. Rio de Janeiro, RJ: Forense Universitária.

Barros, C. A., \& Guimarães, L. A. M. (1999). Lesões por esforços repetitivos - L.E.R: Aspectos psicológicos. In L. A. M. Guimarães \& S. Grubits (Eds.), Saúde mental e trabalho. Vol. 1 (pp. 73-86). São Paulo, SP: Casa do Psicólogo.

Basaglia, F. (1980). A psiquiatria alternativa: Contra o pessimismo da razão, o otimismo da prática. São Paulo, SP: Brasil Debates.

Borges, L. de O., \& Argolo, J. C. T. (2002). Estratégias organizacionais na promoção da saúde mental do indivíduo podem ser eficazes? In M. da G. Jacques \& W. Codo (Eds.), Saúde mental e trabalho: Leituras (pp. 271-295). Petrópolis, RJ: Vozes.

Borsoi, I. C. F. (2005). O modo de vida dos novos operários: Quando purgatório se torna paraíso. Fortaleza, CE: Editora da Universidade Federal do Ceará.
Codo, W., Sampaio, J. J. C., \& Hitomi, A. H. (1992). Indivíduo, trabalho e sofrimento. Petrópolis, RJ: Vozes.

Codo, W., Soratto, L., \& Vasques-Menezes, I. (2004). Saúde mental e trabalho. In J. C. Zanelli, J. E. Borges-Andrade \& V. B. Bastos (Eds.), Psicologia, organizações e trabalho no Brasil (pp. 277299). Porto Alegre, RS: Artmed.

Codo, W., \& Vasques-Menezes, I. (1999). Burnout: Síndrome da desistência. In W. Codo (Ed.), Educação: Carinho e trabalho (pp. 237-255). Petrópolis, RJ: Vozes.

Dejours, C. (1992). A loucura do trabalho: Estudo de psicopatologia do trabalho. São Paulo, SP: Cortez/Oboré.

Dejours, C. (1994). A carga psíquica do trabalho. In C. Dejours, E. Abdoucheli, \& C. Jayet. Psicodinâmica do trabalho: Contribuições da escola dejouriana à análise da relação prazer, sofrimento e trabalho (pp. 21-32). São Paulo, SP: Atlas.

Dejours, C. (2005). A banalização da injustiça social. Rio de Janeiro, RJ: Editora da Fundação Getúlio Vargas.

Filgueiras, J. C., \& Hippert, M. I. (2002). Estresse: Possibilidades e limites. In M. da G. Jacques \& W. Codo (Eds.), Saúde mental e trabalho: Leituras (pp. 112-129). Petrópolis, RJ: Vozes.

Jacques, M. da G. C. (2003, jan./jun.). Abordagens teórico-metodológicas em saúde/doença mental e trabalho. Psicologia \& Sociedade, 15(1), 97-116.

Le Guillant, L., Roelens, R., Begoin, J., Béquart, P., Hansen, M., \& Lebreton, F. (1984, jul./ago./set.). A neurose das telefonistas. Revista Brasileira de Saúde Ocupacional, 17(47), 7-11.

Lima, M. E. A. (1997). A dimensão psicológica. In M. E. A. Lima, J. N. G. Araújo \& F. P. A. Lima (Eds.), L.E.R. - Lesões por esforços repetitivos: Dimensões ergonômicas e psicossociais (4960). Belo Horizonte, MG: Health.

Lima, M.E. A. (2002). Esboço de uma crítica à especulação no campo da saúde mental e trabalho. In M. da G. Jacques \& W. Codo (Eds.), Saúde mental e trabalho: Leituras (pp. 50-81). Petrópolis, RJ: Vozes.

Lima, M. E., Assunção, A. A., \& Francisco, J. M. S. D. (2002). Aprisionado pelos ponteiros de um relógio: O caso de um transtorno mental desencadeado no trabalho. In M. da G. Jacques \& W. Codo (Eds.), Saúde mental e trabalho: Leituras (pp. 209-246). Petrópolis, RJ: Vozes.

Marx, K. (1983). O Capital. São Paulo, SP: Abril Cultural.

Marx, K. (1993). Manuscritos econômico-filosóficos. Lisboa, Portugal: Edições 70.

Rigotto, R. M., \& Rocha, L. E. (1993). Como conduzir-se diante dos agravos à saúde dos trabalhadores? In J. T. P. Buschinelli, L. E. Rocha \& R. M. Rigotto (Eds.), Isto é trabalho de gente? - Vida, doença e trabalho no Brasil (pp. 275-293). Petrópolis, RJ: Vozes.

Rocha, L. E., \& Nunes, E. D. (1994). Os primórdios da industrialização e a reação dos trabalhadores: Pré-30. In J. T. P. Buschinelli, L. E. Rocha \& R. M. Rigotto (Eds.), Isto é trabalho de gente? Vida, doença e trabalho no Brasil (pp. 83-96). Petrópolis, RJ: Vozes.

Sampaio, J. J. C., Borsoi, I. C. F., \& Ruiz, E. M. (1998). Saúde mental e trabalho em petroleiros de plataforma: Penosidade, rebeldia e conformismo em petroleiros de produção (On Shore/Off Shore) no Ceará. Fortaleza, CE: Eduece.

Sampaio, J. J. C., \& Messias, E. L. M. (2002). A epidemiologia em saúde mental e trabalho. In M. da G. Jacques \& W. Codo (Eds.), Saúde mental e trabalho: Leituras (pp. 143-171). Petrópolis, RJ: Vozes. 
Sato, L. (2002). Saúde e controle no trabalho: Feições de um antigo problema. In M. da G. Jacques \& W. Codo (Eds.), Saúde mental e trabalho: Leituras (pp. 31-49). Petrópolis, RJ: Vozes.

Sato, L., \& Bernardo, M. H. (2005, out./dez.). Saúde mental e trabalho: Os problemas que persistem. Ciência \& Saúde Coletiva, 10(4). Retirado em 04 fev. 2006, da Base de Dados Scientific Eletronic Library On line (SciELO), de http://www.scielo.br/ scielo.php

Scopinho, R. A. (2003). Vigiando a vigilância: Saúde e segurança no trabalho em tempos de qualidade total. São Paulo, SP: Annablume.

Tavares, M. (2004). A clínica na confluência da história pessoal e profissional. In W. Codo (Ed.), O trabalho enlouquece? - Um encontro entre a clínica e o trabalho (pp. 53-103). Petrópolis, RJ: Vozes.

Thompson, E. P. (1981). A miséria da teoria ou um planetário de erros: Uma crítica ao pensamento de Althusser. Rio de Janeiro, RJ: Jorge Zahar.

Vasques-Menezes, I. (2004). Por onde passa a categoria trabalho na prática terapêutica? In W. Codo (Ed.), O trabalho enlouquece? - Um encontro entre a clínica e o trabalho (pp. 23-32). Petrópolis, RJ: Vozes.
Izabel Cristina Ferreira Borsoi é Psicóloga, Mestre em Psicologia Social, Doutora em Sociologia, professora adjunta do Departamento de Psicologia e do Programa de Pós-Graduação em Psicologia da Universidade Federal do Ceará. Endereço para corresspondência: Rua Carolino de Aquino, 421, apto 2003, Fátima, Fortaleza, CE, 60050-140. cristinaborsoi@uol.com.br

\section{Da relação entre trabalho e saúde à relação entre trabalho e saúde mental}

Izabel Cristina F. Borsoi

Recebido: 30/06/2006

$1^{a}$ revisão: 16/10/2006

$2^{\mathrm{a}}$ revisão: 03/11/2006

$3^{\mathrm{a}}$ revisão: 20/12/2006

Aceite final: 06/03/2007 